\title{
Children of Substance Abusing Parents: Child Behavior Data of Brazilian Service
}

\begin{abstract}
Keywords: Children of addicted parents; Family relations; Family interventions; Risk factors and prevention

Abstract

Determining the relevant risk factors and protective factors as wel as the correlation between them is an important tool for preventing substance abuse. A case-control study of addiction and its risk factors was performed in 305 children and adolescents in Brazilian families (418 years of a ge) living in Sã oPaulo. This study found that, among other risk fac tors, pa rents with an a d dic tion to illic it drugsc a used substantia lly harm to the psychological development of their children than parents with only an alcohol addiction. This effect was increased for younger children, who later developed psychiatric disordersorengaged in risky behaviors. Ourdata, which were obta ined from an exclusively Brazilia $n$ sample, demonstrate that the children of addicted parents are an important risk group and should be further studied. The findings of this study confirm the need for more studies with this population and more rea dily available preventive interventions for the child ren of addicted parents.
\end{abstract}

In the field of prevention, questions regarding the etiology of addiction cannot be addressed without discussing the risk related to the factors involved in a whole interaction. We are unable to discern which factors are more influential when individual and family resilience are considered [1], as it is established that internal and external factors may increase a child's vulnerability to mental health problems.

Factors related to the home environment, particularly the effects of paternal care and addiction, have a strong influence on the risk of substance abuse among children [2,3]. Parental substance abuse is frequently associated with all types of maltreatment; almost $80 \%$ of the families who come to the attention of Child Protective Services in the USA have some type of substance abuse problem [4]. In a Brazilian study [5], high rates of child mental health problems (22.4\% in children aged 4-17 years) and severe physical punishment ( $10.1 \%$ in children aged $0-17$ years) were found, confirming the need to explore the potential association between those risk factors and parental drug misuse more closely.

The relationship between parental substance abuse and child neglect is stronger than the relationship between parental substance abuse and other types of maltreatment [6]. McCoy and Keen conducted a parental factors study in which $85 \%$ of the sample listed substance abuse as one of the top two causes of child mistreatment, with poverty as the other leading cause [7].

Manning et al. reported that the number of children raised by substance-dependent parents has significantly increased as well as the rates of substance abuse and dependence [3]. The interactions between the increase in this population of children and the rates of substance use are unavoidable and reinforce a model of addictive behavior.

\section{Journal of}

Addiction \& Prevention

\section{Roberta Payá ${ }^{1,2 \star}$, Barbara Giustti ${ }^{1,2}$, Ana Paula Saccani ${ }^{1}$, Érika Bergamini Mastandréa ${ }^{1}$ and Neliana Buzi Figlie ${ }^{1,2}$}

${ }^{1}$ Alcohol and Drug Unit of the Federal University of São Paulo (UNIAD) EPM, São Paulo, Brazil

${ }^{2}$ Utilitarian Center for Intervention and Support for Children of Addicted Parents (CUIDA), Federal University of São Paulo EPM, São Paulo, Brazil

*Address for Correspondence

Roberta Paya, Alcohol and Drug Unit of the Federal University of São Paulo (UNIAD) EPM, São Paulo, Brazil, E-mail: robertapaya@hotmail.com

Submission: 26 April, 2015

Accepted: 01 September, 2015

Published: 05 September, 2015

Copyright: @ 2015 Paya R, et al. This is an open access article distributed under the Creative Commons Attribution License, which permits unrestricted use, distribution, and reproduction in any medium, provided the original work is properly cited.

Reviewed \& Approved by: Dr. Robert L. Peralta, Associate Professor of Sociology, University of Akron, USA

In a national study Figlie et al. investigated a group 225 members of 63 families; they found that alcohol dependence was the most common type of substance dependence among fathers [8]. In addition, $58 \%$ of the spouses were at risk for developing mental disorders, and $59 \%$ of the children required some type of mental health treatment.

The majority of studies have shown that there are significant data demonstrating a relationship between parents with alcohol problems and the consequences of such problems on their children or family systems. Moreover, despite the well-documented evidence of child outcome among mothers who used drugs during pregnancy, there is relatively little information on the predictive relation on children of drug dependent fathers $[9,10]$.

Understanding the characteristics of this subset of children at particular risk is critical for the implementation of preventive programs, services, and policies. The purpose of this study was to evaluate the effects of father's addiction at the national level and to explore data regarding alcohol and illicit drug problems in a sample of Brazilian families with an emphasis on children. This study took place in a specialized service organization for children and adolescents of parents with substance dependence located in the outskirts of Sao Paulo, an area with high population density, widespread poverty, few services and other social vulnerabilities.

\section{Methods}

\section{Setting}

The study group was enrolled in a selective prevention program for the children of parents with substance dependence (Support Center for Children and Adolescents from Families with Alcohol and Drug Problems (CUIDA), Federal University of SãoPaulo, Brazil. The control group was recruited from the pediatric outpatient clinic of a 
public health care facility. Data collection from the study and control group was conducted on the outskirts of the city of SãoPaulo, Brazil.

\section{Inclusion and exclusion criteria}

The study group inclusion criteria included the presence of one randomly selected child from each family. Children (4-18 years of age) of alcohol or drug-dependent fathers who achieved a positive score on the Family CAGE (Cut down on drinking; Annoyed by complaints about drinking; Guilty about drinking; had an Eye-opener first thing in the morning) questionnaire and who were accompanied by a caregiver at the prevention program were included. The exclusion criteria included children of addicted mothers and children who were not accompanied by a caregiver at the selected prevention program. It is important to note that most of the drug-dependent family members at this service organization were male; there were too few children with substance-using mothers to be included in the sample.

The control group inclusion criterion was one randomly selected child from each family (4-18 years old) with no substance dependence history in the family the according with the interview process applied at the pediatric outpatient clinic by the specialized team. The exclusion criterion for the control group also included children who were not accompanied by a caregiver.

\section{Subjects}

A case-control study was conducted with a convenience sample; the participants were paired by sex and age. One child per family was randomly selected to avoid biasing the sample, which ultimately included 305 children representing 305 families. The interview was conducted with the caregiver (all were female: mothers, grandmothers, aunts and step mothers). The father had alcohol dependence in $44 \%$ ( $n=133$ ) of the families, and the father had illicit-drug dependence in $16 \%(n=50)$ of the families; $40 \%(n=122)$ of the families had no parental substance dependence. Of the 305 families evaluated, $71 \%$ $(\mathrm{n}=214)$ were categorized as socio economic class D or E (see the measures section for the socio economic ratings).

The mean age of the parents was 38 years old $(\mathrm{SD}=11.6)$. Of the 305 fathers, 132 (43\%) were white, and 173 (57\%) were black. Of the 305 mothers, 161 (53\%) were white, and 144 (47\%) were black. Many of the fathers had manual labor jobs, whereas the majority of the mothers worked as house cleaners or housekeepers. Of the entire sample, $52 \%(\mathrm{n}=158)$ of the fathers and $50.5 \%(\mathrm{n}=154)$ of the mothers had not completed elementary school.

The children's ages ranged from 4 to 18 years. Of the children, 124 were between 4 and 8 years of age, 86 were between 9 and 12 years of age, and 95 were between 13 and 18 years of age. The mean age of the children with a father with alcohol dependence was 10.38 , the mean age of children with a father with illicit drug dependence was 8.44, and the mean age of children in the control group was 10.30 $(\mathrm{p}=0.007)$. Eight percent of the sample was between 17 and 18 years of age; of the $17-18$ year olds, only $24 \%(n=6)$ had completed high school. Of the $31 \%$ of the sample who should have completed 9 years of schooling, only $14 \%$ had completed this amount of education. With respect to the number of siblings, $16 \%(\mathrm{n}=50)$ had no siblings, $56 \%$ $(\mathrm{n}=170)$ had one or two brothers, and $28 \%(\mathrm{n}=85)$ had more than three brothers. The demographic data for the sample are included in Table 1. With respect to substance use among the children, $98 \%$ ( $\mathrm{n}=$
299) reported not having used any type of substance, and 4(1.4\%) had experimented with alcohol. All four were children of a father with alcohol dependence.

Because some interviews were incomplete, there were eight missing participants who were missing data related to the Child Behavior Checklist protocol [11]. The total CBCL sample included 297 children and adolescents. Of this sample, $21 \%(n=62)$ had nonclinical scores, and 79\% $(n=235)$ had clinical scores $(\mathrm{p}<0.001)$. Of the $79 \%$ who received clinical scores, the findings indicated that 105 children were in the alcohol group, 48 children were in the illicit-drug group and 82 children were in the control group.

\section{Measures}

A team of previously trained psychologists conducted the interviews. A 60-minute interview was conducted with the caregiver of the children following the sequence described below.

Child behavior checklist: The child behavior checklist $[11,12]$ consists of 20 items aimed at evaluating social competence and 118 items aimed at evaluating behavioral problems in children and adolescents. This checklist has been translated into more than 85 languages, and the Brazilian Portuguese version has been reported to have a sensitivity of $87 \%$. This checklist has been reported to be capable of discriminating between individuals with and without psychopathology.

Brazilian economic classification criterion: The Brazilian Economic Classification Criterion [13] is a socio economic rating system that evaluates the purchasing power of urban families and individuals. This system classifies the population using the sum of points obtained on the questions, which include the following: schooling of the head of the family on an 8-point scale ranging from 0 to 21 points, and the points awarded according to the number of durable goods owned by the family. The social classes are divided as follows: Class E (0-19 points); Class D (20-34 points); Class C (3558 points); Class B (59-88 points); and Class A ( 89 points or more). Class A represents the most favored social stratum, whereas Class E represents the least favored social stratum.

In order to assurance the inclusion criterion of the sample, the study has applied the Family CAGE questionnaire. The Family CAGE questionnaire is a screening instrument that consists of four questions used to identify family problems related to alcohol consumption; this instrument associated with the interview process applied in both services could assurance the father's diagnoses. For that, the instrument was adapted to the Portuguese language by Mansur and Monteiro [14]. The Portuguese version was adapted for use with illegal drugs for this study. The used cut-offs correspond to an affirmative answer.

\section{Statistical analysis}

Statistical analysis was performed using the Statistical Package for the Social Sciences (SPSS v17.0. Chicago, IL, USA). To understand the associations between the groups and the socio-demographic characteristics, the chi-square test and Fisher's exact test were used. To compare the means of the ages of the children between the groups, an analysis of variance was used. 
Table 1: Demographic data related to the families and children in the study $(N=305)$.

\begin{tabular}{|c|c|c|c|c|c|c|}
\hline \multirow[b]{2}{*}{ Characteristic } & \multicolumn{3}{|c|}{ Paternal dependence } & \multirow{2}{*}{$\begin{array}{l}\text { Total } \\
\text { N (\%) }\end{array}$} & \multirow[t]{2}{*}{ Statistic } & \multirow[b]{2}{*}{$\mathbf{P}$} \\
\hline & $\begin{array}{c}\text { Alcohol } \\
\text { n (\%) }\end{array}$ & $\begin{array}{l}\text { Drugs } \\
\mathrm{n}(\%)\end{array}$ & $\begin{array}{c}\text { Controls } \\
\text { n (\%) }\end{array}$ & & & \\
\hline \multicolumn{2}{|c|}{ Marital status of the parents } & & & & $F_{2,257}=24,544$ & $0.001^{* *}$ \\
\hline Single & $4(3)$ & $4(8)$ & $2(2)$ & $10(3)$ & & \\
\hline Married/steady partner & $94(71)$ & $24(48)$ & $84(69)$ & $202(66)$ & & \\
\hline Divorced/separated & $31(23)$ & $21(42)$ & $32(26)$ & $84(27.5)$ & & \\
\hline Widower & $4(3)$ & $1(2)$ & $4(3)$ & $9(3)$ & & \\
\hline Socioeconomic status & & & & & $\mathrm{F}_{2,257}=13,282$ & 0,056 \\
\hline $\mathrm{B}$ & $4(3)$ & $2(4)$ & $3(2,5)$ & $9(3)$ & & \\
\hline C & $32(24)$ & $7(14)$ & $43(35)$ & $82(27)$ & & \\
\hline $\mathrm{D}$ & $90(68)$ & $39(78)$ & $74(61)$ & $203(66,5)$ & & \\
\hline$E$ & $7(5)$ & $2(4)$ & $2(1,5)$ & $11(3,5)$ & & \\
\hline \multicolumn{7}{|l|}{$\begin{array}{c}\text { Age of the parents, mean } \\
\qquad S D\end{array}$} \\
\hline Total & $133(100)$ & $50(100)$ & $122(100)$ & $305(100)$ & & \\
\hline \multicolumn{7}{|l|}{ Sex of the child } \\
\hline Male & $66(50)$ & $32(64)$ & $62(51)$ & $160(52)$ & & \multirow{2}{*}{$\begin{array}{l}0.203 \\
3,218\end{array}$} \\
\hline Female & $67(50)$ & $18(36)$ & $60(49)$ & $145(48)$ & & \\
\hline \multirow[t]{2}{*}{$\begin{array}{l}\text { Age of the child, average } \\
\qquad \pm S D\end{array}$} & & & & & $F_{2,257}=5,076$ & $\begin{array}{c}0.007^{* *} \\
5,076 \\
p=0,007\end{array}$ \\
\hline & $10.38 \pm 4.2$ & $8.44 \pm 3.4$ & $10.30 \pm 4.2$ & & & \\
\hline Level of child's education & & & & & $F_{2,257}=23,396$ & $0.013^{*}$ \\
\hline Illiterate & $4(3)$ & $0(0)$ & $13(11)$ & $17(6)$ & & \\
\hline Preschool & $28(21)$ & $17(34)$ & $18(15)$ & $63(21)$ & & \\
\hline$<9$ years of schooling & $66(50)$ & $29(58)$ & $54(44)$ & $149(49)$ & & \\
\hline High school (complete) & $3(2)$ & $0(0)$ & $3(2.5)$ & $6(2)$ & & \\
\hline Does not know & $3(2)$ & $0(0)$ & $3(2.5)$ & $6(2)$ & & \\
\hline Total & $133(100)$ & $50(100)$ & $122(100)$ & $305(100)$ & & \\
\hline
\end{tabular}

Chi-square test or Fisher's exact test p-values

F test (ANOVA) p-value for mean comparisons- * $p<0.05 p<0.01$

\section{Ethical issues}

All of the participants provided written informed consent, and their anonymity was guaranteed. The study design was approved by the Human Research Ethics Committee of the Federal University of SãoPaulo -School of Medicine (protocol no. 917/99).

\section{Results}

\section{Demographic data}

Family: Of the 305 families evaluated, 214 (71\%) were categorized as poverty stricken (class D or E). There were no significant differences between the socioeconomic classes in the entire sample.

Children: The mean age was 10.38 for the children of fathers with alcohol problems, 8.44 for the children of fathers with drug problems and 10.30 for the children in the control group $(p=0.007)$. Of the sample, 124 (41\%) were between the ages of 4 and 8 years old, 86 (28\%) were between 9 and 12 years old, and 95 (31\%) were between 13 and 18 years of age. Of the children between 13 and 18 years of age, $8 \%$ were $17-18$ years old; only 6 (24\%) of the $17-18$ year olds had completed high school. Of the $31 \%$ of the sample that should have completed the obligatory nine years of schooling, only $14 \%$ had done so (Table 1).

\section{Child behavior data}

Analysis of the CBCL $(n=297)$ revealed that the children of drugdependent parents showed greater number of clinical aspects related to the psychological development of their children than fathers with alcohol addiction. The aspects that were affected were as follows: withdrawal, somatic complaints, social problems, thought problems, delinquent rule-breaking behavior, externalizing, and total behavioral problems. The children of alcohol-dependent parents showed higher rates for the following 4 subsets that constitute the CBCL: anxious/ depressed, attention problems, aggressive behavior, and internalizing (Table 2).

Table 3 shows the distribution of the CBCL subscale results by age bracket with Pearson's chi-square test statistics to determine the correlation between this variable and the other variables. We determined that the age bracket correlated with the following: 
Table 2: Child behavior checklist data, by substance $(N=297)$

\begin{tabular}{|c|c|c|c|c|c|}
\hline \multirow{2}{*}{$\begin{array}{l}\text { Child Behavior Checklist } \\
\text { Clinical Conditions of The Children }\end{array}$} & \multicolumn{3}{|c|}{ Substance Groups } & \multirow{2}{*}{$\begin{array}{c}\text { Total } \\
297(100 \%)\end{array}$} & \multirow{2}{*}{$\begin{array}{c}p^{* *} \\
<0.001\end{array}$} \\
\hline & $\begin{array}{c}\text { Alcohol } \\
105(80.8 \%)\end{array}$ & $\begin{array}{l}\text { Drugs } \\
48(98 \%)\end{array}$ & $\begin{array}{c}\text { None } \\
82(69 \%)\end{array}$ & & \\
\hline Withdrawal & $29(22)$ & $29(59)$ & $6(5)$ & $64(21.5)$ & $<0.001$ \\
\hline Somatic Complaints & $12(9)$ & $12(24.5)$ & $1(1)$ & $25(8)$ & $<0.001$ \\
\hline Anxiety/ Depression & $26(20)$ & $3(6)$ & $8(7)$ & $37(12.5)$ & $=0.001$ \\
\hline Social Problems & $22(17)$ & $14(29)$ & $10(8.5)$ & $46(15.5)$ & $=0.003$ \\
\hline Thought Problems & $10(8)$ & $6(12)$ & $4(3)$ & $20(7)$ & $<0.001$ \\
\hline Attention Problems & $26(20)$ & $4(8)$ & $11(9)$ & $41(14)$ & $=0.001$ \\
\hline Delinquent Behavior & $11(8.5)$ & $12(24.5)$ & $6(5)$ & $29(10)$ & $<0.001$ \\
\hline Aggressive behavior & $26(20)$ & $8(16)$ & $11(9)$ & $45(15)$ & $=0.027$ \\
\hline Sexual Problems & $63(48.5)$ & $11(22)$ & $53(45)$ & $127(42)$ & $<0.001$ \\
\hline Internalizing & $61(47)$ & $11(22)$ & $25(21)$ & $97(33)$ & $<0.001$ \\
\hline Total Behavioral Problems & $69(53)$ & $27(55)$ & $33(28)$ & $129(43)$ & $=0.001$ \\
\hline
\end{tabular}

Chi-square test; Fisher's exact test

anxiety/depression $(\mathrm{p}=0.002)$, delinquent rule-breaking behavior ( $\mathrm{p}$ $=0.001)$, aggressive behavior $(\mathrm{p}=0.018)$, sexual problems $(\mathrm{p}<0.001)$, and total behavioral problems $(\mathrm{p}=0.010)$. No significant correlations were observed between the age brackets and any of the remaining CBCL subsets (Table 3).

\section{Discussion}

According to Richter, Leppin, and Gabhainn, and Richter et al., it is possible to identify an association between the socio economic status of a family and the development of maladaptive behavior in children and adolescents $[15,16]$.

Of this sample, 214 families (71\%) were considered poverty stricken (economic class D or E). A socioeconomic trait is not in itself a determining factor, and a family with a low-income does not necessarily have substance dependence-related or violence-related problems. However, when low socioeconomic status is accompanied by other risk factors, it could increase the risk for developmental problems among children and adolescents [17].

Having separated parents might be a risk factor when accompanied by other factors [18]. Although the majority of the families investigated in the present study consisted of couples, the proportion of separated parents was greater among the children of drug-dependent parents than among other groups. We observed that the proportion of families with an unplanned parenthood was also higher among this group. It is important to consider the association between socioeconomic status and the arrangement of the Brazilian families investigated because various characteristics within families could make such families high risk.

The method used to identify differences between the groups in this study was the probability of a child developing behavioral and/ or emotional problems. The findings from this study revealed that substance abuse by fathers is more harmful when it involves illicit drug use, and these harms are associated with other factors, such as the age of the child.

Data showed that impairments in externalizing factors were
Table 3: Child behavior checklist data by subscale and age bracket $(N=297)$.

\begin{tabular}{|c|c|c|}
\hline \multirow{2}{*}{$\begin{array}{l}\text { Clinical Conditions of The children } \\
\text { associated with the Age }\end{array}$} & Clinical & \multirow{2}{*}{$p^{\star \star}$} \\
\hline & $297(100 \%)$ & \\
\hline Delinquent rule-breaking behavior & $29(10)$ & \\
\hline $4-8$ & $19(15)$ & \multirow{3}{*}{0.001} \\
\hline $9-12$ & $7(9.5)$ & \\
\hline $13-18$ & $3(3)$ & \\
\hline Aggressive behavior & $45(15)$ & \\
\hline $4-8$ & $26(21)$ & \multirow{3}{*}{0.018} \\
\hline $9-12$ & $10(13.5)$ & \\
\hline $13-18$ & $9(9)$ & \\
\hline Total behavior problems & $129(43)$ & \\
\hline $4-8$ & $66(53)$ & \multirow{3}{*}{$<0.010$} \\
\hline $9-12$ & $33(45)$ & \\
\hline $13-18$ & $30(30)$ & \\
\hline Anxious/depressed & $37(12.5)$ & \\
\hline $4-8$ & $16(13)$ & \multirow{3}{*}{0.002} \\
\hline $9-12$ & $13(18)$ & \\
\hline $13-18$ & $8(8)$ & \\
\hline Sexual problems & $127(43)$ & \\
\hline $4-8$ & $16(13)$ & \multirow{3}{*}{$<0.001$} \\
\hline $9-12$ & $27(36.5)$ & \\
\hline $13-18$ & $84(85)$ & \\
\hline
\end{tabular}

Chi-square test; Fisher's exact test

greater among children of drug-dependent fathers. These children tended to develop problems such as withdrawal, somatic complaints, social and thought problems, delinquent behavior, externalizing problems and total behavioral problems. These results are consistent with data found in the literature $[19,20]$. For instance drug-dependent parents spend less time with their children and tend to monitor the children less, providing the children with fewer social stimuli [21]. Studies have suggested that the children of drug-dependent parents 
are at increased risk for maladaptive behavior because they are subjected to numerous risk factors associated with the substance abuse and dependence of their parents [22].

According to Bailey, Hill, Oesterle, and Hawkins, parental monitoring and externalizing behavior in children are associated with generational models [23]. From this perspective, it should be highlighted that substance abuse is often a behavior that is learned from other generations and identified in other generations.

The children of alcohol-dependent parents, however, were more vulnerable to developing emotional problems such as depression and anxiety, attention problems, internalizing aspects and aggressive problems. These findings can be associated with Rocha et al. and Murray et al., once they reported that children of addicted parents are more likely to develop depression, anxiety, conduct disorder, and social phobia [24,25]. Furthermore Feitosa and ZanotiJeronymo\&Carvalho, highlighted that the self-esteem of children of alcoholic parents is worse than that of children of nonalcoholic parents $[6,26]$.

Another aspect to be associated with the factor of alcohol dependence is that it affects the functioning of families and has an effect on the mood of the children. Eiden et al. found that alcoholdependent fathers were nearly incapable of reaching out to their children, thereby affecting the emotional status of the children in fact [2].

When the groups of the children of alcohol-dependent and drug-dependent fathers were compared with the control group, the effect of parental addiction became evident. Having an alcohol or drug-dependent father was shown to have a negative effect on the emotional and behavioral functioning of children. Although 235 of the participants received a clinical score on at least one CBCL subscale, the worst consequences were found among the children whose fathers had a problem with illicit drug use.

It was also investigated the substance use among children. From the total sample, $98 \%(n=299)$ reported not having used any type of substance, and four children (2\%) had experimented with alcohol. All four of these children had fathers with alcohol dependence according to the caregivers' perception. It is likely that this behavior could easily be denied by the parents or not shared by their children. However, the findings of a national study [27] showed that the mean age of drinking onset in Brazilian adolescents has decreased; the mean age is currently approximately 13.9 years old. According to the World Health Organization (2001), between the ages of 12 and 18 years, mental and behavioral disorders caused by the use of psychoactive substances could emerge. It is important to note that the mean age bracket was 8-10 years of age. Thus, analyzing this evidence from the point of view of age alone makes it difficult to predict whether these children would develop problematic substance use.

When considering age as a potential risk factor, the $\mathrm{CBCL}$ results varied based on the age range of the child. Children in the developmental phase were shown to be more vulnerable. As shown in Table 3, the three age brackets analyzed in the present study (4/89/12-13/18) reflected greater or lesser vulnerability to specific CBCL subscales. Children in the $4 / 8$ bracket were more likely to present with behavioral problems, aggressiveness, and delinquency than the children in the other age brackets. Children in the 9/12 bracket, a phase in which children gain a deeper understanding of their parent's problems and of family dysfunction, were the most vulnerable to depression and anxiety. Children in the 13/18 bracket were the most vulnerable to sexual problems. In the $13 / 18$ bracket, children experience a sexual awakening and the onset of sexual activity occurs.

\section{Limitations}

The present study has some limitations. First, this study focused on a high-risk, relatively homogeneous low-socioeconomic status population sample from a Latin American country; the study facilitated the identification of risk factors related to specific types of child mental health problems in a population that has rarely been systematically studied. Our study results are likely generalizable to other disadvantaged communities located in the outskirts of highly populated cities in developing countries. These results have important implications for designing effective interventions to address the development of child mental health problems in similar populations.

This aspect had also impact on the data, which needed to be a cross-sectional data thus the economic status of this population has keeping requiring many geographic adaptation, including the fact that many families have moving from their homes in order to find a better condition of life and work opportunities.

Another point, because the study has considered children enrolled in the prevention service, the diagnosis ofsubstance misusewasmade during theprocess of enrollingthe families of the participants, and for the dependence criteria, it was taken into account one drug of choice only (licit or illicit drug). However, this interview process did not assurance the possibility to have fathers using more than on type of substance.

Furthermore, the questionnaire was administered to the caregivers of the children evaluated (CBCL), which could result in bias due to the perception of the caregivers and their understanding of the questions.

\section{Conclusions}

Although the findings of the present study showed that both alcohol dependence and illicit drug dependence of fathers are very harmful to the development of their children because they considerably increase the likelihood that they will experience emotional and behavioral problems.

The data also confirms that findings between national sample and international studies are similar, once those children of drugdependent fathers showed greater impairment with respect to externalizing behaviors than the children of alcohol-dependent fathers. Although the contribution of this study with a Brazilian sample must be highlighted. Furthermore, the children of drugdependent fathers tended to develop problems related to behavior (withdrawal, somatic complaints, social problems, thinking problems, delinquent rule-breaking behavior, and total behavioral problems). Children of alcohol-dependent fathers were more likely to develop emotional problems such as anxiety, depression, attention problems, internalizing behavior, and aggressive behavior. In clinical terms, children in the 4-8 year age bracket were the most vulnerable and should be the primary target of early preventive interventions. This 
age bracket was found to be more vulnerable to developing behavioral problems, aggressiveness, and delinquency than the other age groups. Physical aggression and severe diseases among family members were shown to be significant risk factors.

The combination of these factors cries out for better, more comprehensive, readily available prevention strategies that can address complex correlated risk factors, the multiple needs of Brazilian families with parents who misuse drugs, and the characteristics of their communities indicating the need of more research on this population.

\section{References}

1. Jordan S (2010) The promotion of resilience and protective factors in children of alcoholics and drug addicts. Bundesgesundheitsblatt Gesundheitsforschung Gesundheitsschutz 53: 340-346.

2. Eiden RD, Colder C, Edwards EP, Leonard KE (2009) A longitudinal study of social competence among children of alcoholic and nonalcoholic parents: role of parental psychopathology, parental warmth, and self-regulation. Psycho Addict Behav 23: 36-46.

3. Manning V, Best DW, Faulkner N, Titherington E (2009) New estimates of the number of children living with substance misusing parents: results from UK national household surveys. BMC Public Health 9: 377.

4. Winton MA, Mara BA (2001) Child abuse and neglect: multidisciplinary approaches. Boston: Allyn and Bacon.

5. Bordin IA, Duarte CS, Peres CA, Nascimento R, Curto BM, et al. (2009) Severe physical punishment: risk of mental health problems for poor urban children in Brazil. Bull World Health Organ 87: 336-344.

6. Feitosa HN, Ricou M, Rego S, Nunes R (2011) Mental health of children and adolescents: epidemiological, assistance and bioethical considerations. Rev Bioét 19: 259-275.

7. McCoy ML, Keen SM (2009) Child abuse and neglect. New York: Psychology Press.

8. Figlie N, Fontes A, Moraes E, Payá R (2004) Filhos de dependentes químicos com fatores de risco bio-psicossociais: necessitam de um olhar especial? Children of addicted parents with bio-psychosocial risk factors: Do they need a special care? Rev Psiquiatr Clin 31: 53-62.

9. Bagner DM, Sheinkopf SJ, Miller-Loncar C, LaGasse LL, Lester BM, et al. (2009) The effect of parenting stress on child behavior problems in high-risk children with prenatal drug exposure. Child Psychiatry Human Dev 40: 73-84

10. Payá R, Santoro LG, Vieira DL, Figlie NB (2015) Logistic regression to assess risk factors in off spring from Brazilian families with alcohol and drug problems. Int Arch Addict Res Med 1: 1-7.

11. Achenbach TM (1991) Manual for child behavior checklist 4-18, 1991 profile. Department of Psychiatry, University of Vermont.

12. Bordin IAS, Mari JJ, Caeiro MF (1995) Validaçao da versaobrasileira do "Child Behavior Checklist" (CBCL) (Inventrio de Comportamentos da Infância e Adolescência): dados preliminaries. Rev ABPAPAL 2: 55-66.
13. Associação Nacional de Empresas de Pesquisa (1997) Critério de Classificação Econômica. São Paulo, Brazil: Associação Nacional de Empresas de Pesquisa.

14. Mansur J, Monteiro MG (1983) Validation of the "CAGE" alcoholism screening test in a Brazilian psychiatric inpatient hospital setting. Braz J Med Biol Res 16: $215-218$

15. Richter M, Leppin A, Nic Gabhainn S (2006) The relationship between parental socio-economic status and episodes of drunkenness among adolescents: findings from a cross-national survey. BMC Public Health 6 : 289.

16. Richter M, Erhart M, Vereecken CA, Zambon A, Boyce W, et al. (2009) The role of behavioral factors in explaining socio-economic differences in adolescent health: a multilevel study in 33 countries. Soc Sci Med 69: 396403.

17. Fatori D, Bordin IA, Curto BM, de Paula CS (2013) Influence of psychosocial risk factors on the trajectory of mental health problems from childhood to adolescence: a longitudinal study. BMC Psychiatry 13: 31

18. Anda RF, Brown DW, Felitti VJ, Dube SR, Giles WH (2008) Adverse childhood experiences and prescription drug use in a cohort study of adult HMO patients. BMC Public Health 8: 198.

19. Eiden RD, Coles CD, Schuetze P, Colder CR (2014) Externalizing behavior problems among polydrug cocaine-exposed children: Indirect pathways via maternal harshness and self-regulation in early childhood. Psychol Addict Behav 28: 139-153.

20. Linares TJ, Singer LT, Kirchner HL, Short EJ, Min MO, et al. (2006) Mental health outcomes of cocaine-exposed children at 6 years of age. J Pediatr Psychol 31: 85-97.

21. Barnard M (2005) Intervening with drug dependent parents and their children: What is the problem and what is being done to help? Glasgow, UK: Centre for Drug Misuse Research, University of Glasgow.

22. Backett-Milburn K, Wilson S, Bancroft A, Cunningham-Burley S (2008) Challenging childhoods young people's accounts of 'getting by' in families with substance use problems. Childhood 15: 461-479.

23. Bailey JA, Hill KG, Oesterle S, Hawkins JD (2009) Parenting practices and problem behavior across three generations: monitoring, harsh discipline, and drug use in the intergenerational transmission of externalizing behavior. Dev Psychol 45: 1214-1226.

24. Rocha MM, Rescorla LA, Emerich DR, Silvares EF, Borsa JC, et al. (2012) Behavioural/emotional problems in Brazilian children: findings from parents' reports on the child behavior checklist. Epidemiol Psychiatr Sci 22: 329-338

25. Murray J, Anselmi L, Gallo EA, Fleitlich-Bilyk B, Bordin IA (2013) Epidemiology of childhood conduct problems in Brazil: systematic review and meta-analysis. Soc Psychiatry Psychiatric Epidemiol 48: 1527-1538.

26. Zanoti-Jeronymo DV, Carvalho AM (2005) Autoconceito, desempenho escolar e avaliação comportamental de crianças filhas de alcoolistas [Selfconcept, academic performance and behavioral evaluation of the children of alcoholic parents]. Rev Bras Psiquiatr 27: 233-236.

27. Pinsky I, Sanches M, Zaleski M, Laranjeira R, Caetano R (2010) Patterns of alcohol use among Brazilian adolescents. Rev Bras Psiquiatr 32: 242-249. 